\title{
SISTEM INTENSIFIKASI TANAMAN PADI SRI MELALUI PEMANFAATAN MIKROORGANISME LOKAL DALAM PEMBUATAN KOMPOS DAPAT MENINGKATKAN POPULASI MIKROBA TANAH (STUDI KASUS DI DESA SIDODADI KABUPATEN DELI SERDANG)
}

\author{
SYSTEM OF RICE INTENSIFICATION BY A LOCAL MIKROORGANISME USAGE IN \\ PRODUCING THE COMPOST FERTILIZER CAN IMPROVE LAND MICROBIA \\ POPULATION (CASE STUDY AT DESA SIDODADI KABUPATEN DELI SERDANG)
}

\author{
Eka Maida ${ }^{1}$ )
}

\begin{abstract}
System of Rice Intensification (SRI) by a Local Microorganisme Usage (MOL) in Producing the Compost Fertilizer (Case Study at Desa Sidodadi Kabupaten Deli Serdang) is expected to maintain the fertile of land, improve land microbia population and to preserve the environment at once capable to maintain or improve land productivity. The agriculture system with SRI is applied by using organic material such as fruif waste whis is fermented to produced MOL used as decomposer in composing proges. This reseach studied microbia population where an organik agricaltural system (SRI) has been applied. The reseach was comparedl of mikroba population soil also whith how effect SRI aplication between chemical fertilizer for the managemental in Sidodadi village. Using compost MOL at SRI improved microbia population soil by the result of soil analysis either chemically and biologically the uses of MOL compost is far better compared for environmental the uses of an-organic fertilizer. The SRI pattern practiced at Desa Sidodadi was an agricultural work environmentally friendly using organic fertilizer as source of nutrients improve physical, chemical and biological properties of soil as well in increasing production yield.
\end{abstract}

Keyword : System of Rice Intensification (SRI), Local Microorganisme (MOL), land microbia population.

\section{PENDAHULUAN}

Upaya peningkatan produksi padi dengan pengelolaan yang intensif melalui pemberian pupuk kimia adakalanya tidak meningkatkan produksi seperti yang diharapkan, dan bahkan dapat mengalami penurunan produksi. Gejala ini disebabkan oleh degradasi kesuburan tanah akibat praktek pemupukan yang hanya bertumpu pada pemberian pupuk anorganik (kimia) dengan jenis dan dosis yang tidak rasional. Degradasi kesuburan tanah dicirikan oleh rendahnya kandungan bahan organik dan unsur hara dalam tanah, pada kondisi semacam ini sifat fisik, kimia dan biologi tanah menjadi kurang baik (Syekhfani, 2000).

Dampak dari pemakaian pupuk kimia dan pestisida secara terus menerus tidak kelihatan dalam waktu yang singkat, namun akan terlihat dalam kurun waktu yang relatif lama. Kejadian ini dapat dilihat pada akhir tahun 80 -an dimana produktivitas lahan mulai menurun akibat gencarnya pemakaian pupuk anorganik pada program Insus yang tanpa disertai pupuk organik. Pupuk anorganik dapat memberikan dampak negatif bila diaplikasi secara terus menerus. Pupuk anorganik dapat mempengaruhi perkembangan mikroorganisme dalam tanah. Mikroorganisme tersebut tidak dapat menguraikan bahan organik di dalam tanah. Akibatnya sisa-sisa pupuk yang tidak terserap oleh akar tanaman terakumulasi dalam tanah dan mempengaruhi kondisi tanah, tanah menjadi keras, menggumpal, dan $\mathrm{pH}$ menurun. Produktivitas tanah sebagai daya dukung terhadap pertumbuhan dan produksi tanaman di atasnya dapat menurun. Apabila kondisi seperti ini tidak diatasi maka terjadi levelling off, yaitu kondisi dimana pertambahan input tidak lagi mampu meningkatkan produksi tanaman (Djamhari, 1993).

Peningkatan pemakaian pupuk buatan dan pestisida terkadang menimbulkan masalah bagi lingkungan. Seiring dengan berkembangnya kesadaran tentang pertanian berkelanjutan, makin disadari pentingnya pemanfaatan bahan organik dalam pengelolaan hara di dalam tanah. Penggunaan bahan organik di dalam tanah diyakini dapat memperbaiki sifat fisik, kimia dan biologi tanah (Engersta, 1991 dalam Hadanyani 2003).

Lebih lanjut Sutanto (2002) dalam Ruskandi, (2006) menjelaskan bahwa pertanian organik dapat

1) Staf Pengajar Fakultas Pertanian Universitas Malikussaleh 
didefinisikan sebagai suatu sistem produksi pertanaman yang berazaskan daur ulang hara secara hayati. Berdasarkan definisi tersebut pertanian organik merupakan pertanian ramah lingkungan yang bersifat hukum pengembalian (low of return) yang berarti suatu sistem yang berusaha untuk mengembalikan semua jenis bahan organik ke dalam tanah, baik dalam bentuk residu dan limbah pertanian maupun ternak yang selanjutnya bertujuan untuk memenuhi unsur hara pada tanah yang mampu memperbaiki status kesuburan tanah terutama struktur tanah. Dengan demikian dapat dikatakan bahwa pertanian organik banyak memberikan keuntungan ditinjau dari aspek peningkatan kesuburan tanah serta aspek lingkungan dalam mempertahankan keseimbangan ekosistem. Sistem pertanian organik dapat diterapkan dengan salah satu cara yaitu melalui sistem intensifikasi tanaman padi atau yang lebih dikenal dengan System of Rice Intensification (SRI)

Sistem Intensifikasi tanaman padi (SRI) telah terbukti sukses diterapkan di sejumlah negara terutama di Madagaskar. Sistem ini merupakan salah satu sistem pertanian organik yaitu budidaya tanaman padi yang intensif dan efisien dengan proses manajemen berbasis pada pengelolaam tanah, air dan tanaman. Pada SRI ini petani diarahkan untuk memberikan masukan pada usaha taninya dengan menggunakan potensi alam. Mikroorganisme yang tersedia di alam dapat digunakan sebagai dekomposer dalam proses pengomposan limbah organik dan kotoran binatang. Mikroorganisme ini diharap dapat berfungsi secara optimal dalam tanah sehingga kesuburan tanah dapat meningkat (Berkelaar, 2002).

Limbah organik seperti sisa-sisa tanaman dan kotoran ternak tidak bisa langsung diberikan ke tanaman. Limbah organik harus dihancurkan/dikomposkan terlebih dahulu oleh mikroba tanah menjadi unsur hara yang dapat diserap oleh tanaman. Proses pengomposan alami ini memakan waktu yang sangat lama, antara enam bulan hingga setahun, sampai bahan organik tersebut benar-benar dapat digunakan tanaman. Proses pengomposan dapat dipercepat dengan menggunakan mikroba dekomposer yang berkemampuan tinggi. Penggunaan mikroba dapat mempersingkat proses dekomposisi dari beberapa bulan menjadi beberapa minggu saja (Isroi, 2004).

Petani desa Sidodadi Kecamatan Beringin Kabupaten Deli Serdang Sumatera Utara yang dijadikan sebagai objek penelitian pada awalnya melakukan kegiatan pertanian sama seperti petani lain yaitu menggantungkan pertaniannya pada penggunaan pupuk kimia yang dapat mempercepat masa panen dan hasil yang berlipat. Namun lambat laun hasil panen tidak lagi surplus bahkan untuk memenuhi kebutuhan warga Sidodadi mereka kerap mengambil dari daerah lain. Petani di desa Sidodadi mulai berpikir bagaimana kembali meningkatkan hasil produksi dan kalau mungkin mengurangi ketergantungan pada pupuk kimia dan air secara berlebihan. Muncul inisiatif untuk menggantikan pupuk kimia dengan pupuk organik melalui pola tanam SRI.

Pupuk yang digunakan dalam SRI di Desa Sidodadi adalah pupuk kompos yang berasal dari bahan organik seperti kotoran hewan, limbah organik, jerami yang proses dekomposisinya dipercepat dengan menggunakan Mikroorganisme Lokal (MOL). Pemupukan dengan pupuk organik MOL dimanfaatkan agar mikroorganisme dalam tanah dapat berperan dengan lebih baik sehingga mampu menguraikan dan menyediakan nutrisi bagi tanaman, menghasilkan humus sebagai media unsurunsur hara sebelum dimanfaatkan oleh akar tanaman (Darmawan, 2006).

Mikroorganisme lokal yang digunakan untuk mempercepat proses pengomposan limbah organik di desa Sidodadi dibiakkan melalui proses fermentasi antara air beras dengan limbah buahbuahan seperti pisang, nenas, jeruk dan pepaya busuk. Hasil biakan MOL digunakan dalam proses pembuatan kompos untuk mempercepat proses dekomposisi limbah organik yang akan diaplikasikan ke lahan pertanian yang menggunakaan pola tanam SRI. Jadi sasaran dari program SRI ini adalah untuk meningkatkan hasil pertanian dengan lahan yang terbatas, menghasilkan produk yang sehat bagi produsen dan konsumen, serta menjaga kelestarian lingkungan

\section{METODE PENELITIAN}

Penelitian ini dilakukan di Dusun Yogya Sidodadi, Kecamatan Beringin, Kabupaten Deli Serdang pada bulan Februari 2007 sampai dengan Juni 2007. Contoh tanah diambil pada areal tanah pertanian yang mengunakan pola SRI dengan memanfaatkan pupuk kompos MOL (PO) sebagai dekomposer pupuk organik dan tanah pertanian mengunakan pupuk kimia (PK). Tanah diupayakan 
dalam keadaan lembab untuk keperluan analisis mikrooganisme di laboratorium. Contoh tanah diambil pada kedalaman $0-20 \mathrm{~cm}$ dengan jarak $500-1000 \mathrm{~m}$ dari beberapa tempat pada lahan yang sama untuk mengetahui populasi mikroorganisme di dalam tanah. Tanah dicampur secara homogen setelah diaduk rata kemudian diambil 500 gr (Syarifuddin, 2002). Contoh tanah uji dianalisis dengan dua kali ulangan di Laboratorium Mikrobiologi, Fakultas Matematika Ilmu Pengatahuan Alam, Universitas Sumatera Utara.

Populasi dari masing-masing kelompok mikroba yaitu mikroba tanah pertanian yang mengunakan pola SRI dengan memanfaatkan pupuk kompos MOL (PO) sebagai dekomposer pupuk organik dan tanah pertanian mengunakan pupuk kimia (PK) dapat dihitung berdasarkan rumus:

$$
C F U / m l=\frac{\text { rata }- \text { rata.Jumlah koloni per petri agar } x d f}{\text { volume suspensi biakan yang disebarkan }}
$$

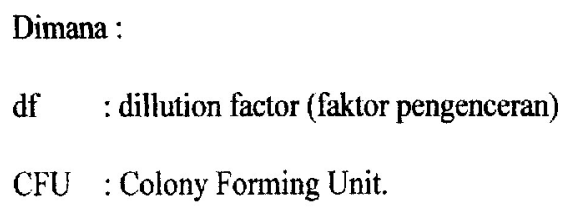

Analisis data dilakukan dengan Uji-T yaitu dengan membandingkan rata-rata parameter pengamatan terhadap masing-masing jumlah populasi mikroba tanah. Data yang diperoleh dari hasil penelitian dianalisis secara statistik dengan menggunakan model sebagai berikut :

$$
\begin{aligned}
& t H=\frac{\mu 1-\mu 2}{s \sqrt{(1 / n 1+1 / n 2)}} \\
& \mathrm{tH} \quad=\text { t-Hitung } \\
& \mu 1 \quad=\text { rata-rata contoh tanah dengan pemberian kompos yang memanfaatkan MOL } \\
& \mu 1 \quad=\text { rata-rata contoh tanah yang memakai pupuk kimia } \\
& n \quad=\text { jumlah masing-masing contoh tanah yang diambil } \\
& s \quad=\text { simpangan baku }
\end{aligned}
$$

Kriteria pengujian adalah $\mathrm{H} 0: \mu 1=\mu 2$ dan $\mathrm{H} 1: \mu 1 \neq \mu 2$, sehingga $\mathrm{H} 0$ akan diterima bila $\mathrm{tH}<\mathrm{t}$-Tabel (Sudjana. 2002).

\section{HASIL DAN PEMBAHASAN}

\section{Populasi Mikrobia Tanah}

Pada pemberian kompos MOL (PO) jumlah populasi mikroba tanah jauh lebih tinggi dibandingkan dengan pemberian pupuk anorganik (PK) baik populasi bakteri maupun jamur. Jumlah populasi mikrobia tanah dapat dilihat pada Gambar I sebagai berikut: Dari Gambar 1 menunjukkan bahwa jumlah populasi bakteri dan jamur lebih tinggi pada perlakuan $\mathrm{SO}$ (pupuk organik) dibandingkan dengan perlakuan PK(pupuk kimia) pada setiap jenis media yang digunakan. Jumlah populasi mikroba baik bakteri maupun jamur menunjukkan populasi mikroba tertinggi terdapat pada bahan organik yang menggunakan kompos MOL sebagai dekomposer dibandingkan dengan penggunaan pupuk kimia.

Menurut Muniapan (1998) dalam Kastono (2005) menyatakan pemberian bahan organik ke dalam tanah dapat merangsang aktivitas enzim tanah dan mikroba, aktivitas enzim total tanah tergantung pada enzim ekstraseluler dan jumlah enzim dalam sel mikroba yang mati dan hidup. Kompos banyak mengandung mikroorganisme (fungi, aktinomicetes, bakteri dan algae) yang berfungsi untuk proses dekomposisi lanjut terhadap bahan organik tanah. 
Penambahan kompos ke dalam tanah, tidak hanya jutaan mikroorganisme yang ditambahkan ke dalam tanah, tetapi mikroorganisme yang ada di dalam tanah juga terpacu untuk berkembang biak. Selain itu aktivitas mikroorganisme di dalam tanah juga menghasilkan hormon-hormon pertumbuhan seperti auksin, giberellin dan sitokinin yang dapat memacu pertumbuhan dan perkembangan akar-akar rambut sehingga daerah pencarian unsur-unsur hara semakin luas.

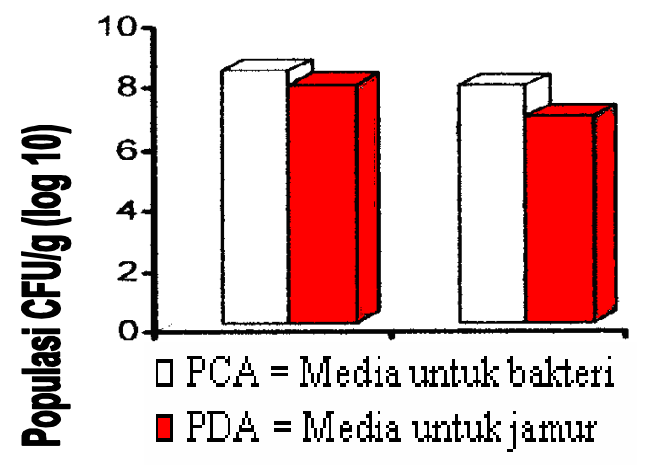

Gambar 1. Populasi Mikroba Tanah.

\section{KESIMPULAN dan SARAN}

1. Pemberian kompos MOL dapat meningkatkan populasi mikroba tanah dan hasil analisis tanah baik secara kimia dan biologi pengunaan kompos MOL jauh lebih baik dibandingkan dengan penggunaan pupuk anorganik.

2. Pemanfaatan kompos MOL dari limbah buahbuahan dan sisa hasil pertanian dapat menekan terjadinya pencemaran lingkungan.

\section{DAFTAR PUSTAKA}

Anonim. (2006). Sistem informasi agribisnis. Kabupaten Deli Serdang 1-13. Diakses dari http://www.deptan.go.id/sipoa/sumut/deliser dang/index.htm

Anonim. (2002). Proyek farmers field school. Ecological Agriculture at The Enviromental Educatioan Centre PPLH Celoliman, East Java. Indonesia. 1-2. Diakses dari www.peneco.ch
Adiningsih, J. (2000). Peranan bahan organik tanah dalam sistem usaha tani konservasi. Laporan. Pusat Penelitian dan Pengembangan Peternakan. Jakarta.

Admin. (2003). Yeast makhluk di balik minuman keras. Artikel. Lembaga Pengkajian Pangan Obat-Obatan dan Kosmetika Majelis Ulama. Jakarta.

Alexander, M. (1977). Intruduction to Soil Microbiology. John Wiley and Sons. New York.

BAPEDALDA JATIM. (2007). Kompos, alternatif problem sampah. Diakses dari http://bapedal-jatim.info/indek.php

Bekti, E., \& Surdianto,Y. (2001). Pupuk kompos untuk meningkatkan produksi padi sawah. Laporan Seri: Tanaman pangan/PAATP 005: 113/546.

Berkelaar, D. (2002). Sistem intensifikasi padi (the system of rice intensification - sri) : sedikit dapat memberi lebih banyak. Buletin ECHO Development Notes, January 2001. Issue 70, Halaman 1-6. Diterjemahkan oleh Indro Surono, ELSPPAT, Bogor.

Buckman, H.O., \& Brady, N. C. (1982). Ilmu tanah. Terjemahan Soegiman. Bharata Karya Aksara, Jakarta.

Burelle, N. K., Kloepper, J., \& Reddy, M. (2005). Population dynamics of plant growthpromoting rhizobacteria as transplant amendments and their effects on indigenous rhizosphere microorganisms. Applied Soil Ecology 31(1):91-100.

Chae, Y. M., \& Tabatabai, M. A. (1986). Mineralization of nitrogen in soil amended with organic waste. Jurnal Environment Quality. 15(2):1993 1998.

Dafni, M. T. (2001). Pengaruh pembalikan orgadec dan nitrogen terhadap laju pengomposan sampah organik serta kualitas kompos yang terbentuk dalam rangka perbaikan kebersihan lingkungan. Tesis. Program 
Pascasarjana Universitas Sumatera Utara. Medan.

Dalzell, H. W., Biddles`tone, A. J., Gray, K. R., \& K. Thuraijan. (1991). Pengelolaan tanah : produksi dan penggunaan kompos pada lingkungan tropis dan sub tropis di dalam limbah padat di Indonesia. Masalah atau Sumber Daya. Yayasan Obor Indonesia. Jakarta. 19(4):152172.

Darmawan. (2006). Metode SRI (System of Rice Intensification). Buletin Departemen Pekerjaan Umum Republik Indonesia. Jakarta.

Darmijati, S. (1987). Tanggap Empat varietas tanaman terhadap bahan organik. Pemberitaan Penelitian Sukaramai No. 10.

Deptan. (2006). Pertemuan koordinasi dan sinkronisasi PLA TA. 2006. Rakorsin 12 s/d 14 Pebruari 2006, Surabaya. Diakses dari http:llwww.deptan.go.id/pla/buletin/.

Djamhari. (1993). Pemasyarakatan teknologi budidaya pertanian qrganik di Desa Sembalun Lawang Nusa Tenggara Barat. Jurnal Sains dan Teknologi Indonesia. 5(1):5.

Erwiyono, R. (1994). Pengaruh pemberian pupuk kandang dan aerasi terhadap mutu kompos limbah organik pabrik kertas. Jurnal Mikrobiologi Indonesia. 11(2): 2-3

Foth, D. H. (1993). Dasar-dasar ilmu tanah. Gajah Mada University Press. Jogjakarta.
Galileo. (2007). Pengaruh limbah tomat dan EM-4 terhadap percepatan pengomposan sampah organik. Diakses dari http: //www. blogspot. com/tag/enlpercepatan.

Hadi, S. P. (2003). Aspek sosial AMDAL. Sejarah, Teor, Jenis dan Metode. UGM Press, Yogyakarta.

Hakim, N. (1986). Dasar-dasar ilmu tanah. PT Raja Grafindo Persada. Jakarta.

Handayani, R. S., Khusrizal., \& Maisyura. (2006). Pertumbuhan dan hasil tanaman padi (Oriza sativa. L) yang diberi mikoriza pada sistem budidaya SRI (the system of rice intensification). Laporan Akhir Research Grant Pengalian Unggulan Daerah BRR NAD-NIAS Tahun Anggaran 2006.

Handayani. (2003). Sifat kimia entisol pada sistem pertanian organik. Ilmu Pertanian. 10 (2): $63-69$

Handayanto, E. (1998). Pengelolaan Kesuburan Tanah Secara Biologis Untuk Menuju Sistem Pertanian Sustainabel. Jurnal Penelitian Habitat. 10:104-105

Harjowigeno. (1996). Ilmu tanah. Institut Pertanian Bogor. Bogor.

Isroi. (1994). Peranan mikrobiologi tanah dalam meningkatkan ketersediaan hara. Kyusei Nature Farming Societies. Vol: OS/IKNFS/II. Jakarta.

Isroi. (2007). Bioteknologi mikroba untuk pertanian organik, balai penelitian bioteknologi perkebunan indonesia. Laporan Penelitian. Lembaga Riset Perkebunan Indonesia. 